\title{
Crossed Pain and Temperature Sensation Disturbance With Peripheral Facial Palsy Due to a Localized Lateral Inferior Pontine Infarction
}

\author{
Hiromasa Tsuda ${ }^{\mathrm{a}, \mathrm{b}}$, Motohiro Fujiwara ${ }^{\mathrm{a}}$, Ei-ichi Nakao ${ }^{\mathrm{a}}$
}

\begin{abstract}
A 47-year-old man with dyslipidemia abruptly developed pain and temperature sensation disturbance on the left-sided face and rightsided body and extremities, and left-sided peripheral facial palsy. There were not any other neurological symptoms. Cranial magnetic resonance imaging demonstrated a localized infarct lesion in the left lateral inferior pons. The left anterior inferior cerebellar artery (AICA) was demonstrated by magnetic resonance angiography. Consequently, infarction of the left caudomedial branch of AICA might involve spinothalamic tract, spinal trigeminal nucleus and facial nerve. Here, we emphasize that combination of crossed pain and temperature sensation disturbance with peripheral facial palsy is an indicating sign of a localized lateral inferior pontine lesion.
\end{abstract}

Keywords: Anterior inferior cerebellar artery; Facial palsy; Magnetic resonance imaging; Pons; Trigeminal nerve

\section{Introduction}

Based on the anatomical findings, unilateral lateral medullary infarction with involvement of the caudal pons may induce combined symptom of crossed pain and temperature sensation disturbance with ipsilateral peripheral facial palsy [1]. Here, we describe a very rare case of this combined symptom secondary to a localized lateral inferior pontine infarction.

\footnotetext{
Manuscript accepted for publication May 5, 2014

${ }^{a}$ Department of Neurology, Tokyo Metropolitan Health and Medical Corporation Toshima Hospital, Japan

${ }^{\mathrm{b}}$ Corresponding Author: Hiromasa Tsuda, Department of

Neurology, Tokyo Metropolitan Health and Medical Corporation Toshima Hospital, 33-1, Sakaecho, Itabashi-ku, 173-0015, Tokyo,

Japan. Email: hiromasa_tsuda@tokyo-hmt.jp

doi: http://dx.doi.org/10.14740/jmc1785w
}

\section{Case Report}

A 47-year-old man with dyslipidemia abruptly developed pain and temperature sensation disturbance on the left-sided face and right-sided body and extremities, and left-sided peripheral facial palsy. There were not any other symptoms. Complete blood cell counts and blood chemistry were within normal ranges. Chest roentgenogram finding was normal. Electrocardiogram demonstrated no abnormalities. Cranial fluid-attenuated inversion recovery magnetic resonance imaging demonstrated a localized infarction in the left lateral inferior pons (Fig. 1A). The left anterior inferior cerebellar artery (AICA) was demonstrated by magnetic resonance angiography (Fig. 1B). Under anti-platelet agent, he became asymptomatic within 3 weeks.

\section{Discussion}

The facial nucleus in humans is located dorsolaterally in the caudal pons. The corticofacial fibers loop down into the ventral part of the rostral medulla, cross the midline and ascend in the dorsolateral medullary region ipsilaterally to the facial nucleus [1-3]. Involvement of the spinal trigeminal nucleus may cause ipsilateral pain and temperature sensation disturbance in the face [4]. Damage to the lateral spinothalamic tract may induce contralateral pain and temperature sensation disturbance in the body and extremities [4]. Based on these anatomical findings, crossed pain and temperature sensation disturbance with peripheral facial palsy is an indicating sign of dorsolateral medulla with involvement of the caudal pons.

AICA supplies its blood to the lateral inferior pons, middle cerebellar peduncle, anterior inferior cerebellum and inner ear [5]. Therefore, AICA infarction may induce pain and temperature sensation disturbance on the ipsilateral face and contralateral body and extremities, ipsilateral peripheral facial nerve palsy, ipsilateral Horner syndrome, nystagmus, ipsilateral audio-vestibular dysfunction, nausea, vomit, oscillopsia and ataxia [6].

In our patient, pain and temperature sensation disturbance on the left-sided face might be caused by involvement of the 


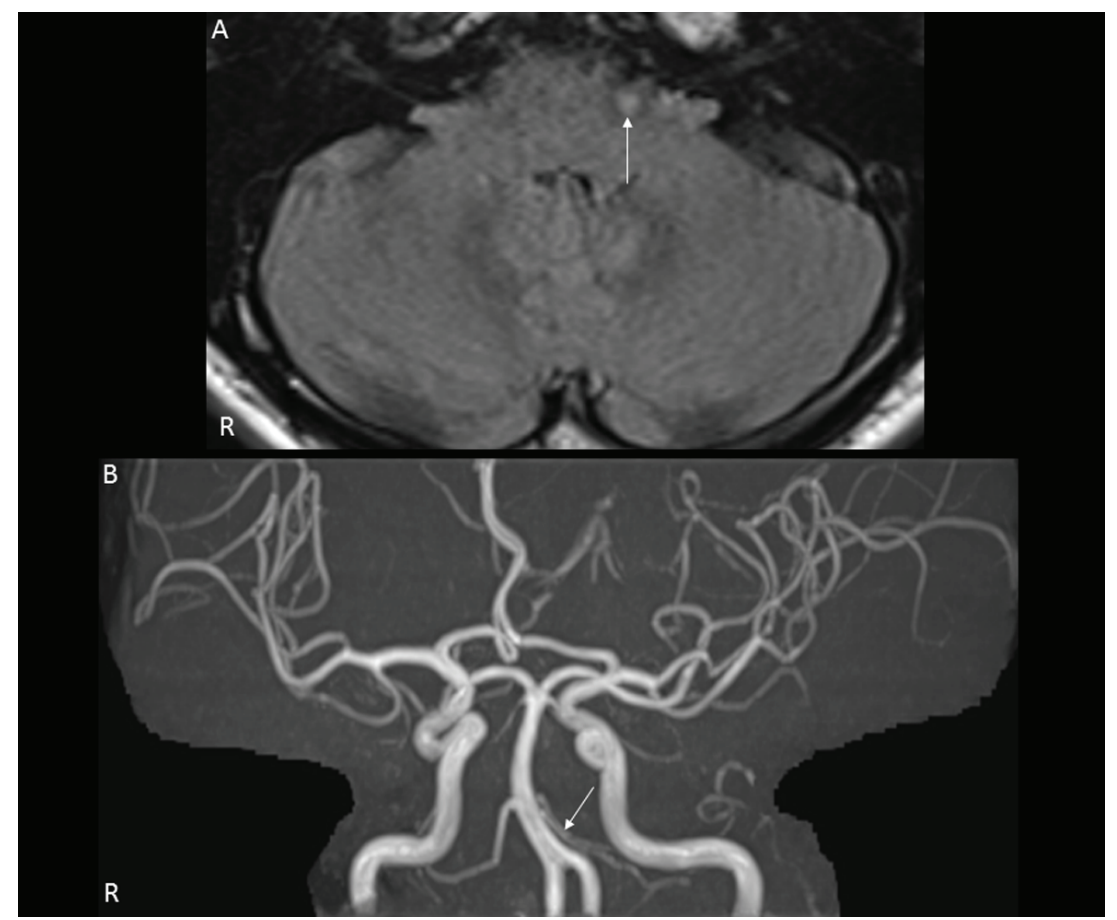

Figure 1. (A) Cranial magnetic resonance imaging on fluid-attenuated inversion recovery image. A localized infarction in the left lateral inferior pons was demonstrated (arrow). (B) Cranial magnetic resonance angiography. The left anterior cerebellar artery was demonstrated (arrow).

left spinal trigeminal nucleus. Pain and temperature sensation disturbance on the right-sided body and extremities might be induced by damage to the left lateral spinothalamic tract. In addition, left-sided peripheral facial palsy might be resulted from facial nerve impairment in the pons. However, no other neurological symptoms were observed. Based on patient's neurological symptoms and cranial magnetic resonance angiography finding, left AICA infarction was denied. Based on cranial magnetic resonance imaging finding, we speculated that the left-sided caudomedial branch of AICA might be infarcted. In conclusion, we emphasize that combined symptom of crossed pain and temperature sensation disturbance with peripheral facial palsy is an indicating sign of not only dorsolateral medulla with involvement of the caudal pons but also a localized lateral inferior pontine lesion.

\section{Conflict of Interest}

The authors declare no conflict of interest.

\section{Grant Support}

None.

\section{References}

1. Fisher CM, Tapia J. Lateral medullary infarction extending to the lower pons. J Neurol Neurosurg Psychiatry. 1987;50(5):620-624.

2. Park JH, Yoo HU, Shin HW. Peripheral type facial palsy in a patient with dorsolateral medullary infarction with infranuclear involvement of the caudal pons. J Stroke Cerebrovasc Dis. 2008;17(5):263-265.

3. Urban PP, Wicht S, Vucorevic G, Fitzek S, Marx J, Thomke F, Mika-Gruttner A, et al. The course of corticofacial projections in the human brainstem. Brain. 2001;124(Pt 9):1866-1876.

4. Terao S, Miura N, Takeda A, Takahashi A, Mitsuma T, Sobue G. Course and distribution of facial corticobulbar tract fibres in the lower brain stem. J Neurol Neurosurg Psychiatry. 2000;69(2):262-265.

5. Naidich TP, Kricheff, II, George AE, Lin JP. The normal anterior inferior cerebellar artery. Anatomic-radiographic correlation with emphasis on the lateral projection. Radiology. 1976;119(2):355-373.

6. Lee H, Kim JS, Chung EJ, Yi HA, Chung IS, Lee SR, Shin JY. Infarction in the territory of anterior inferior cerebellar artery: spectrum of audiovestibular loss. Stroke. 2009;40(12):3745-3751. 